\title{
Behavior of Au species in Au/FeOx Catalysts as a Result of In-Situ Thermal Treatments, Characterized via Aberration-Corrected STEM Imaging
}

\author{
L. F. Allard,* A.Y. Borisevich, ${ }^{*}$ W. Deng, ${ }^{* *}$ Rui Si, ${ }^{* *}$ M. Flytzani-Stephanopoulos** \\ and S.H. Overbury* \\ *Physical Sciences Directorate, Oak Ridge National Laboratory, Oak Ridge, TN 37831 \\ **Department of Chemical and Biological Engineering, Tufts University, Medford, MA 02155
}

In the present study, a series of catalysts derived from a parent 2 at. $\% \mathrm{Au} / \mathrm{Fe}_{2} \mathrm{O}_{3}$ (WGC-ref.\# 60C) material prepared by co-precipitation and calcined in air at $400^{\circ} \mathrm{C}$ ("fresh" catalyst) were characterized, and compared to a catalyst prepared by leaching surface gold from the parent catalyst and exposing it to various treatments, including use in the water-gas shift reaction at $250^{\circ} \mathrm{C}$. [1] A VG HB-603U STEM and a JEOL 2200FS STEM/TEM, both fitted with aberration-correctors on the probe-forming optics, were used in the imaging experiments. Protochips Co. (Raleigh, NC) new Aduro ${ }^{\mathrm{TM}}$ MEMS-based heater technology was utilized in a special specimen holder for the latter instrument, to conduct elevated temperature examinations. [2] Selected results are detailed here.

Figure 1 shows a high-angle annular dark-field (HA-ADF) image of the parent material; the catalyst is composed of $2 \mathrm{~nm} \mathrm{Au}$ particles on 20-40 $\mathrm{nm}$ FeOx support material. Figure 1b shows a typical nanoparticle on the surface of the support, and also an accompanying dispersion of single atoms and small clusters. Characteristic dark features are also commonly seen in the support, which are consistent with void structures. The voids are decorated with the atomic Au species as seen in Fig. $1 \mathrm{c}$, illustrating that some of the $\mathrm{Au}$ in the catalyst is contained within the structure of the oxide. The leaching treatment removed most of the discrete nanoparticles, presumably on the surface. The absence of gold from the surface and sub-surface layers probed by XPS suggests that, for the leached and "fresh" samples, the highly dispersed Au as well as the occasional Au nanoparticle are distributed throughout the bulk of the iron oxide lattice in pores, grain boundaries, at the interface between fused crystallites or within the lattice. Figure 2a-c shows the behavior of the leached sample upon heating. At a nominal $250^{\circ} \mathrm{C}$, little change was noted in the distribution of Au with time $(\sim 10$ min at temperature). No Au particles were observed on the surface. After an additional 2 min at a nominal $500^{\circ} \mathrm{C}$ (this temperature change is effected in about $1 \mathrm{msec}$ with the Aduro ${ }^{\mathrm{TM}}$ heater chip), little change is seen, but after 5 more minutes at temperature, voids have shrunk noticeably or disappeared entirely, the smallest Au species have coalesced into larger particles, and, most notably, $\mathrm{Au}$ species have diffused to the surface and are distributed as $2 \mathrm{~nm}$ crystallites (arrowed in Fig. 2c). These surface crystallites are remarkably stable, maintaining approximately the same size even after annealing to $700^{\circ} \mathrm{C} \mathrm{A}$ further interesting characteristic of the $\mathrm{Au}$ nanoparticles was observed by recording a through-focal series of images of the area outlined in Fig. $2 b$, two of which are shown in Fig. 3a-b. Through-focus images show that the two nanoparticles in the sample at $250^{\circ} \mathrm{C}$ have crystal planes aligned with each other, and with the FeOx host lattice, suggesting topotactic orientations. Particle 1 appears to be positioned at the bottom of the upper void, while Particle 2 is apparently located at the back of the lower void (based on examination of a number of images in the focal sequence). Further results from these samples, as well as samples that were "reduced" and subsequently "re-oxidized" will be presented. [3]

\section{References}

[1] L.F. Allard, et al., J. Electron Microscopy (2009), in press

[2] L.F. Allard, et al., Microscopy Research \& Technique (2003), 72(3): in press

[3] This research at the Oak Ridge National Laboratory's High Temperature Materials Laboratory was sponsored by the U. S. DOE, Office of Energy Efficiency and Renewable Energy, Vehicle Technologies Program, and the Div. of Chemical Sciences, Geosciences, and Biosciences, Office of Basic Energy Science. 


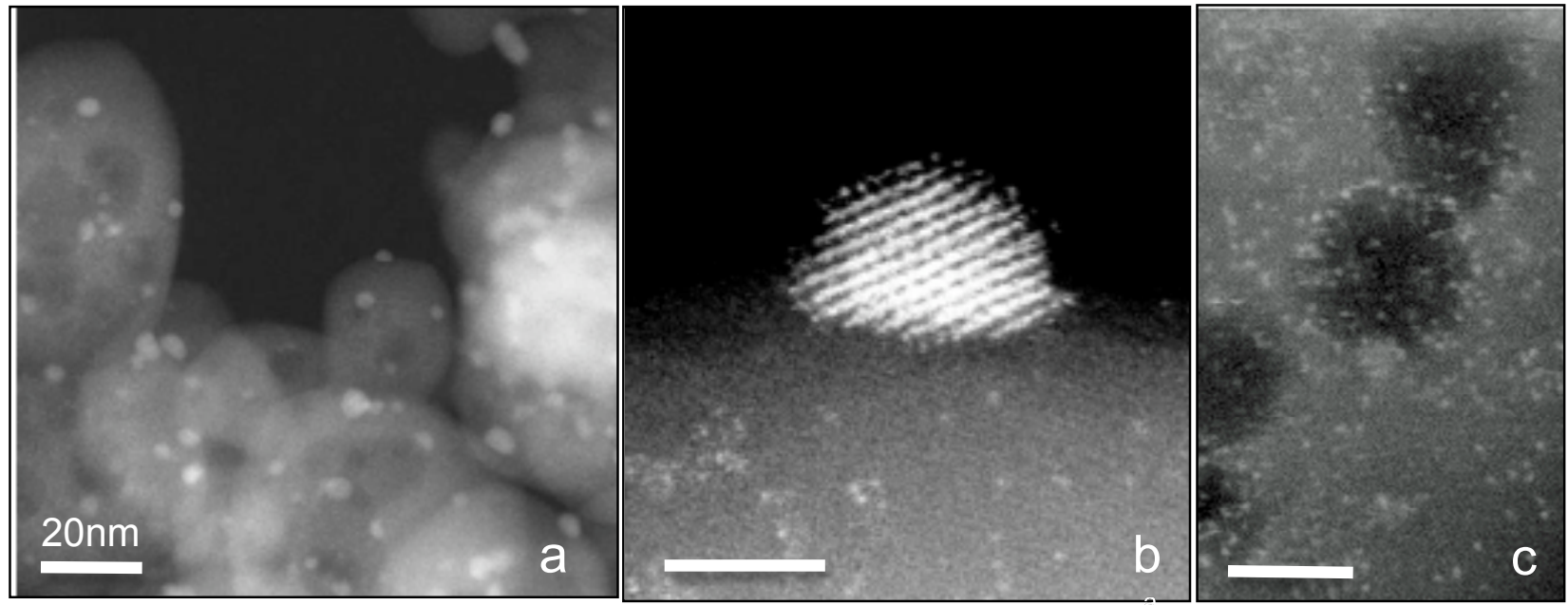

Fig. 1. a) $\mathrm{HA}-\mathrm{ADF}$ images of parent $\mathrm{Au} / \mathrm{Fe}_{2} \mathrm{O}_{3}$ catalyst, showing $2 \mathrm{~nm}$ Au particles, including some on the surface seen with a dispersion of single atoms and clusters (b). Voids are decorated with Au atoms, (c).
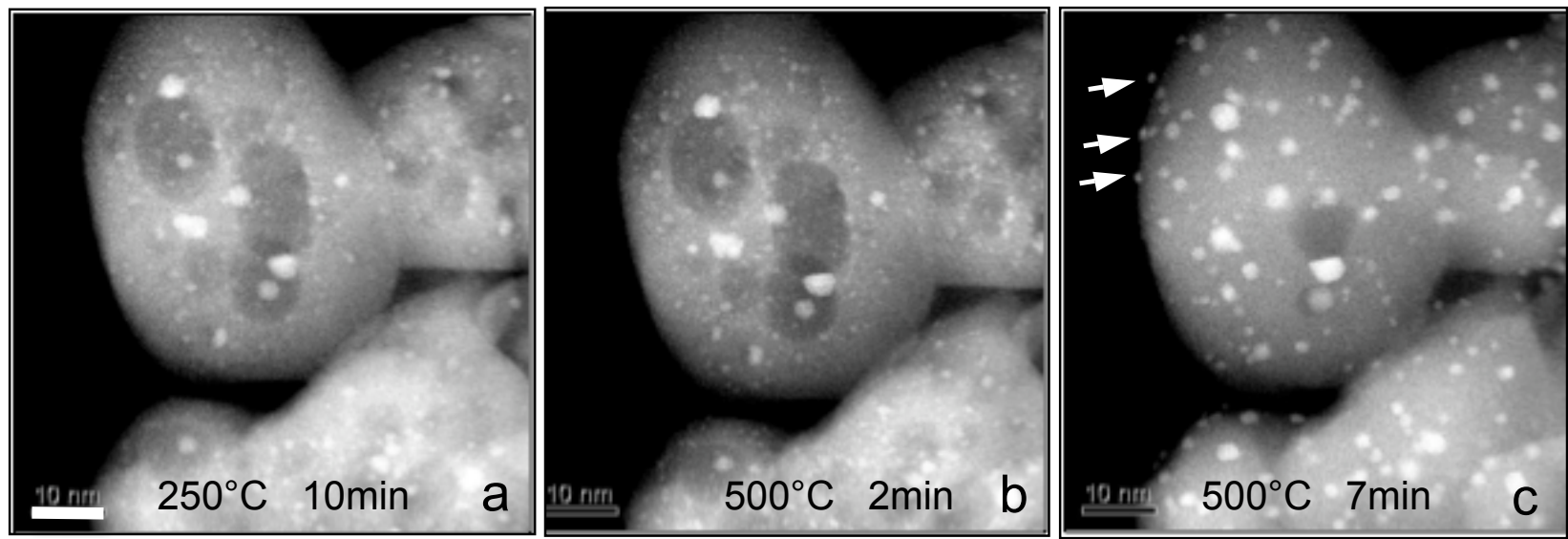

Fig. 2. HA-ADF images of the leached catalyst at $250^{\circ} \mathrm{C}$ (a), and at $500^{\circ} \mathrm{C}$ showing the coalescence of voids and the growth of $\mathrm{Au}$ particles at $500^{\circ} \mathrm{C}$, especially those re-appearing on the surface (arrows in (c)).
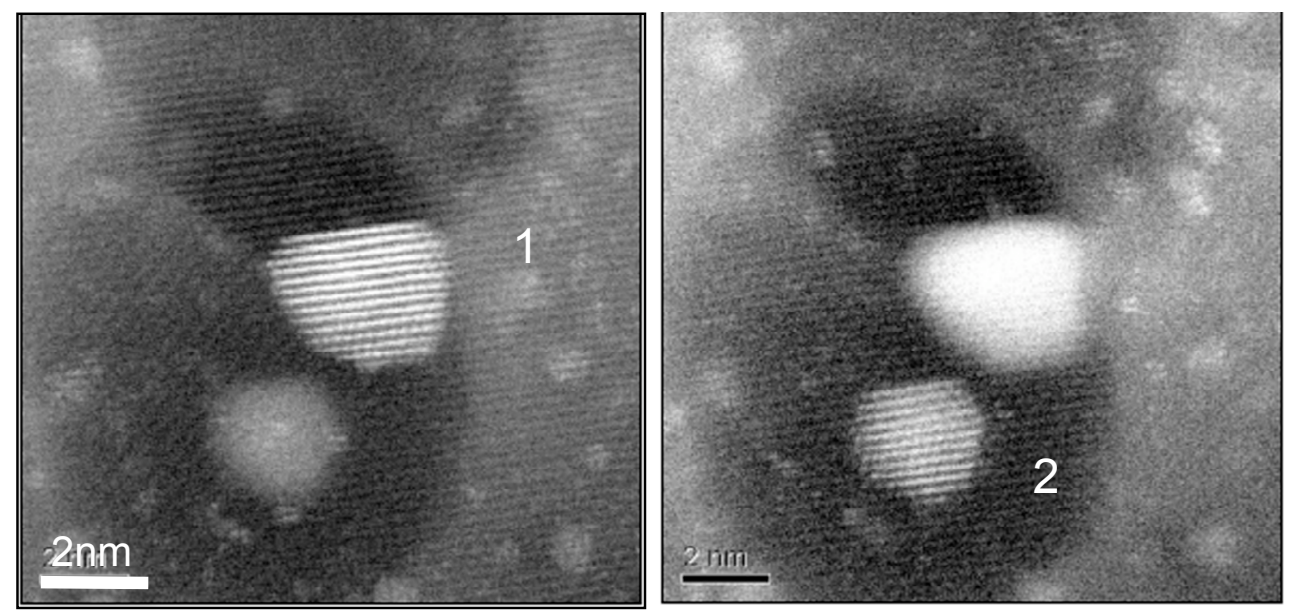

Fig. 3. Through-focus images show that the two nanoparticles in the sample at $250^{\circ} \mathrm{C}$ are topotactically aligned with the $\mathrm{FeOx}$ host lattice. Particle 1 appears to be positioned at the bottom of the upper void, while Particle 2 is apparently located at the back of the lower void. 